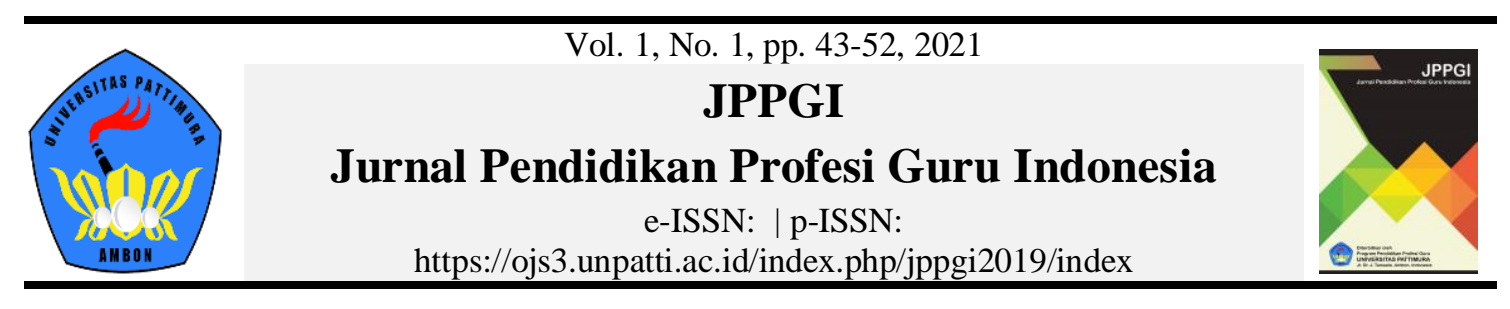

\title{
Student Teams Achievement Division: Hasil Belajar Siswa Materi Segi Empat
}

\author{
Lina Lestari ${ }^{1}$, Magy Gaspersz ${ }^{2 *}$, Maritje Poppy Matulessy ${ }^{3}$ \\ ${ }^{1}$ SMP Negeri 1 Dullah, Tual, Indonesia \\ ${ }^{2}$ Program Studi Pendidikan Matematika, Fakultas Keguruan dan Ilmu Pendidikan, Universitas Pattimura- \\ Ambon, Indonesia \\ ${ }^{3}$ SMP Negeri 4 Ambon, Indonesia \\ *Corresponding e-mail: magygspz.mg@gmail.com
}

Received: 27 August 2020 Accepted: 04 December $2020 \quad$ Online Published: 08 February 2021

\begin{abstract}
Mathematics is one of the subjects considered difficult by students, so the learning outcomes obtained by students are low. The same thing also happened at SMPN 4 Ambon, after observing and interviewing the subject teachers, $58 \%$ of students obtained completeness of student learning in square material. Based on this, the teacher is required to be able to use the learning model so that the material is easily understood or understood by students and creates student-centered learning. So that it can improve student learning outcomes. This study aims to determine the increase in student learning outcomes in class VII-6 SMP Negeri 4 Ambon through the STAD type cooperative learning model with 28 research subjects consisting of 15 male students and 13 female students. Classroom Action Research (CAR) consists of 4 (four) stages, namely: Planning, Implementation, Observation, and Reflection. Data collection is done by observation and tests. The results of observation of the activity showed that there was an increase in each cycle. Likewise with learning outcomes in each cycle has increased namely in the first cycle student learning outcomes by $71.4 \%$ or 20 students increased to $89.3 \%$ or 25 students in the second cycle so an increase of $17.9 \%$.
\end{abstract}

Keywords: Learning outcomes, Cooperative learning, STAD

To cite this article:

Lestary, L., Gaspersz, M., \& Matulessy, M. P. (2021). Students teams achievement division: hasil belajar siswa materi segi empat. JPPGI: Jurnal Pendidikan Profesi Guru Indonesia, 1(1), 43-52.

\section{PENDAHULUAN}

Matematika merupakan salah satu bidang ilmu yang masih dianggap sulit, sehingga berdampak pada hasil belajar siswa (Sofroniou \& Poutos, 2016). Hasil International Mathematical Olympiad (IMO) menginformasikan bahwa Indonesia masih berada pada ranking 14, di mana masih di bawah Cina, Korea, Thailand dan Veitnam sudah berada pada posisi 10 besar (IMO, 2019). Hasil studi lainnya dalam bidang matematika di Provinsi Maluku memberikan informasi bahwa rata-rata siwa hanya mampu mencapai nilai 35,27 (Ratumanan, 2016). Oleh karena itu siswa masih butuh kerja keras untuk memperoleh hasil yang lebih baik. Hal demikian terjadi pada SMP Negeri 4 Ambon. Hasil observasi terhadap pembelajaran matematika di beberapa 
SMP di kota Ambon, menunjukkan bahwa pembelajaran matematika belum maksimal dan masih berpusat pada guru. Siswa kurang berpartisipasi dalam pembelajaran, hal tersebut tampak terlihat ketika guru memberikan pertanyaan tentang materi yang diberikan dan siswa tidak mampu menjawab dengan baik. Selain itu media pembelajaran yang digunakan kurang menarik perhatian siswa sehingga sebagian besar siswa tidak menyimak dengan baik. Guru kurang menumbuhkan percaya diri dalam mengemukakan pendapat dan enggan untuk bertanya jika sulit dalam memahami materi pembelajaran. Akibatnya hasil belajar matematika yang diperoleh siswa sangat rendah. Hasil wawancara langsung dengan guru memberikan informasi hasil belajar siswa pada materi segiempat mencapai nilai ketuntasan secara klasikal sebesar 53,6\%.

Berdasarkan informasi tersebut, maka untuk mengatasi permasalahan terhadap rendahnya hasil belajar siswa, guru perlu merancang pembelajaran sesuai dengan kondisi dan kemampuan siswa serta melibatkan dalam proses pembelajaran sehingga memperoleh hasil yang lebih baik. Rancangan model pembelajaran kooperatif tipe Student Teams Achievement Division (STAD) dipilih untuk mengatasi persoalan pembelajaran tersebut. Model ini sangat membantu siswa bekerja sama dengan teman sejawat dan berkolaborasi dalam memecahkan masalah (Tarim \& Akdeniz, 2008). STAD dianggap cocok untuk membantu siswa berpartisipasi aktif dalam kegiatan pembelajaran sehingga mampu meningkatkan hasil belajar dan mencapai ketuntasan belajar (Wang, 2012).

Model pembelajaran kooperatif tipe STAD terdiri dari lima tahap pembelajaran yaitu persentasi kelas yang dilakukan oleh guru, belajar kelompok dengan menggunakan LKS, kuis individu, peningkatan nilai individu dan penghargaan kelompok. Setiap kelompok terdiri dari 4-5 anggota yang dituntut mandiri dan tidak tergantung pada anggota lain dan setiap siswa mendapat kesempatan yang sama agar kelompoknya mendapat nilai yang maksimal (Tiantong \& Teemuangsai, 2013). Oleh karena itu setiap individu mempunyai tanggung jawab dalam mengoptimalkan pencapaian tujuan pembelajaran matematika agar tercapai hasil belajar yang memuaskan. Dengan model pembelajaran kooperatif tipe STAD akan tercipta kerjasama dan keberhasilan dalam kelompok yang tergantung dari keberhasilan individu (McMaster \& Fuchs, 2002).

Model STAD dapat memberi kesempatan siswa bekerja dalam kelompok, membantu siswa untuk memperbaiki dan meningkatkan keterampilan dan proses kognitif yang dapat meningkatkan aktivitas dan memberi kesempatan kepada siswa untuk berani mengemukakan pendapat (Gencosman \& Doğru, 2012). Penerapan pembelajaran STAD dapat meningkatkan semangat belajar siswa dalam pembelajaran matematika. Dengan demikian tujuan dari penelitian ini adalah untuk mengetahui peningkatan hasil belajar Siswa pada materi segi empat dengan menggunakan model pembelajaran kooperatif Tipe STAD.

\section{METODE}

\section{Tipe Penelitian}

Penelitian yang dilaksanakan berupa penelitian tindakan kelas. Penelitian Tindakan Kelas adalah action research yang dilaksanakan oleh guru di dalam kelas. Action research pada hakikatnya merupakan rangkaian riset yang dilakukan secara siklus, dalam rangka memecahkan masalah, sampai masalah itu terpecahkan. 
Hal penting dari penelitian ini adalah bahwa perencanaan siklus lanjutan harus didasarkan hasil refleksi siklus sebelumnya. Keempat tahap tersebut dapat ditunjukan pada Gambar 1.

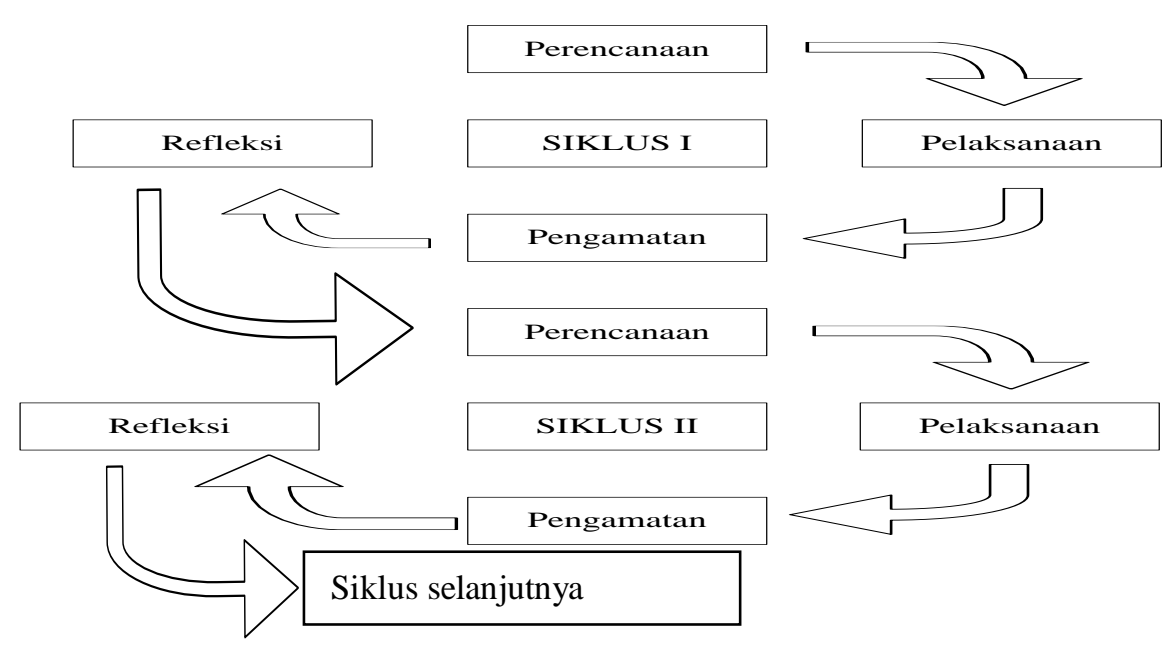

Gambar 1. Diagram model siklus PTK

\section{Populasi dan Sampel}

Populasi dalam penelitian ini adalah siswa kelas VII pada SMP Negeri 4 Ambon yang berjumlah 10 kelas dengan subjek penelitian ini adalah salah satu kelas VII yang berjumlah 28 siswa, terdiri dari 15 laki-laki dan 13 perempuan.

\section{Data dan Sumber Data}

Data dalam penelitian ini berupa data kualitatif dan data kuantitatif. Data kualitatif berupa data observasi terhadap aktivitas guru dan siswa di kelas dan data kuantitatif berupa tes hasil belajar siswa tiap siklus. Sumber data dalam penelitian ini adalah guru dan siswa kelas di salah satu kelas 7.

\section{Perangkat Pembelajaran}

Perangkat pembelajaran yang digunakan adalah rencana pelaksanaan pembelajaran (RPP), lembar kerja siswa (LKS) dan lembar tugas siswa (LKT). Rencana pelaksanaan pembelajaran (RPP) mengacu pada pada silabus dan disesuaikan dengan langkah-langkah pembelajaran Kooperatif tipe STAD dengan menggunakan pendekatan Saintifik. Dalam penelitian dikembangkan dua RPP untuk dua siklus. RPP 01 untuk siklus I dengan dua kali pertemuan, RPP 02 untuk siklus II dengan dua kali pertemuan sedangkan untuk Lembar Kerja Siswa (LKS) dikerjakan secara kelompok dengan rancangan 4 LKS yaitu LKS 01 dan LKS 02 untuk siklus I dan LKS 03 dan LKS 04 untuk siklus II. Lembar Kerja Tugas Siswa (LTS) dirancang untuk dikerjakan secara mandiri untuk empat kali pertemuan dalam 2 siklus. Secara terperinci perangkat pembelajaran yang dikembangkan dalam penelitian ini dapat ditunjukan pada Tabel 1 . 
Tabel 1. Perangkat pembelajaran

\begin{tabular}{ccccl}
\hline Siklus & RPP & LKS & LTS & \multicolumn{1}{c}{ Materi } \\
\hline \multirow{2}{*}{ I } & \multirow{2}{*}{01} & 01 & 01 & Sifat-sifat dan keliling \\
& & 02 & 02 & belah ketupat \\
& & 03 & 03 & Suas belah ketupat \\
II & 02 & 04 & 04 & layang-layang \\
& & Luas layang-layang \\
\hline
\end{tabular}

\section{Instrumen Penelitian}

Instrumen yang digunakan adalah soal tes dan lembar observasi. Instrumen tes berupa tes akhir. Tes akhir dilakukan sebanyak dua kali, yakni tes akhir siklus I dengan materi belah ketupat dan tes akhir siklus II dengan materi layang-layang. Tes akhir berupa soal-soal uraian yang sesuai dengan Kurikulum 2013 yang berlaku pada SMP Negeri 4 Ambon. Tes akhir setiap siklus dilakukan untuk mengukur kemampuan siswa dalam menyelesaikan masalah yang berkaitan dengan belah ketupat dan layang-layang. Lembar observasi yang digunakan dalam penelitian ini adalah lembar observasi untuk siswa dan guru. Masing-masing berisi pernyataan-pernyataan tentang aktifitas pendidik dalam pembelajaran dengan menggunakan model pembelajaran kooperatif tipe STAD dan aktivitas siswa dalam kelompok.

\section{Prosedur Penelitian}

Prosedur PTK secara rinci melalui 4 tahap tiap siklus, yaitu pada siklus I sebagai berikut. 1) Perencanaan; merancang RPP 01, membuat peta konsep, menyusun LKS 01 dan 02, mrngembangkan format evaluasi dan observasi pembelajaran, menyiapkan soal tes akhir siklus I, menetapkan kriteria yaitu pelaksanaan perbaikan dikatakan berhasil jika 85\% siswa mencapa nilai minimal 70 (KKM 270). 2) Tindakan; melaksanakan tindakan mengacu pada RPP yang telah dubuat. 3) Pengamatan; melakukan pengamatan sesuai format observasi guru dan siswa. 4) Refleksi; melakukan evaluasi tindakan dan menganalisis hasil yang diperoleh serta menyimpulkan hal-hal yang perlu diperbaiki dan diperhatikan pada siklus berikut. Dari hasil refleksi siklus I dilakukan perencanaan, pelaksanaan tindakan, pengamatan dan refleksi siklus II sesuai tahap penelitian ini, pembelajaran dapat diselesaikan pada siklus II.

\section{Teknik Pengumpulan Data}

Pengumpulan data dalam penelitian ini adalah tes dan observasi. Tes adalah pertanyaan berupa tulisan yang digunakan untuk mengukur keterampilan, pengetahuan, intelegensi, kemampuan atau bakat yang dimiliki oleh individu atau kelompok (Sternberg, 2015). Tes diberikan setelah tindakan selesai dan dilakukan pada setiap akhir siklus. Tes menggunakan butir soal untuk mengukur hasil belajar siswa, yang berupa uraian sejumlah 5 soal. Hasil dari setiap tes akhir akan digunakan untuk mengukur hasil belajar siswa dan akan dijadikan sebagai patokan melakukan tindakan perbaikan berikutnya. Observasi adalah pengamatan terhadap tingkah laku pada situasi tertentu. Observasi dilakukan untuk mengamati aktivitas siswa dan guru selama kegiatan pembelajaran dengan menggunakan model pembelajaran kooperatif tipe STAD. Data aktivitas siswa dan guru diperoleh dengan lembar observasi. 


\section{Teknik Analisis Data}

Data dalam penelitian ini dianalisis dengan menggunakan analisis data kuantitatif desriptif, yaitu 1) analisis data kualitatif dianalisis dengan model interaktif dikembangkan oleh Miles dan Huberman dengan melalui 3 tahap; a) reduksi data; datadata yang direduksi adalah data hasil observasi guru dan siswa yang dianggap tidak penting, b) penyajian dan pemaparan data; dalam penelitian ini peneliti menyajikan dalam bentuk tabel, c) penarikan kesimpulan; data yang telah disajikan dirangkum dan dibuat kesimpulan. 2) analisis data kuantitatif menggunakan statistik deskriptif, untuk mengetahui kentuntasan.

Tabel 2. Kategori hasil belajar siswa

\begin{tabular}{ccc}
\hline Rata-rata Nilai Siswa & Ketuntasan & Kategori \\
\hline $90-100$ & Tuntas & Sangat Baik \\
$80-89$ & Tuntas & Baik \\
$70-79$ & Tuntas & Cukup \\
$\leq 69$ & Tidak Tuntas & Kurang \\
\hline
\end{tabular}

\section{HASIL DAN PEMBAHASAN}

Penelitian tindakan kelas ini dilaksanakan dalam 2 siklus dan analisis hasil belajara pra silkus pada ditunjukan pada Tabel 3

Tabel 3. Data analisis hasil belajar pra siklus

\begin{tabular}{cccc}
\hline Interval Nilai & Frekuensi & Persentase & Kategori \\
\hline $90-100$ & 0 & $0 \%$ & Tuntas \\
$80-89$ & 2 & $7,2 \%$ & Tuntas \\
$70-79$ & 13 & $46,4 \%$ & Tuntas \\
$\leq 69$ & 13 & $46,4 \%$ & Belum Tuntas \\
\hline Jumlah & 28 & $100 \%$ & \\
\hline
\end{tabular}

Berdasarkan hasil pra siklus, maka perlu adanya upaya peningkatan hasil belajar siswa dalam pembelajaran matematika. Untuk mengatasinya dilakukan tindakan dengan menggunakan model pembelajaran Kooperatif Tipe STAD.

\section{Siklus I}

Hasil observasi pada siklus I dapat ditunjukkan dalam Tabel 4.

Tabel 4. Hasil observasi guru pada siklus I

\begin{tabular}{llll}
\hline \multirow{2}{*}{ Aktivitas Pendidik } & \multicolumn{2}{c}{ Pelaksanaan } & \multirow{2}{*}{ Ket } \\
\cline { 2 - 3 } & Ya & Tidak & \\
\hline Membuka pelajaran dengan berdoa & $\sqrt{ }$ & \\
Memberi motivasi kepada siswa & $\sqrt{ }$ & $\sqrt{ }$ \\
$\begin{array}{l}\text { Apersepsi } \\
\text { Menjelaskan tujuan pembelajaran }\end{array}$ & $\sqrt{ }$ & $\sqrt{ }$ \\
$\begin{array}{l}\text { Menjelaskan mekanisme pembelajaran dan penilaian } \\
\text { yang akan digunakan }\end{array}$ & & \\
$\begin{array}{l}\text { Menjelaskan materi pembelajaran } \\
\text { Memberi kesempatan kepada siswa untuk bertanya }\end{array}$ & $\sqrt{ }$ & \\
Membagi siswa ke dalam 7 kelompok & $\sqrt{ }$ & \\
\hline
\end{tabular}




\begin{tabular}{|c|c|c|c|}
\hline \multirow[t]{2}{*}{ Aktivitas Pendidik } & \multicolumn{2}{|c|}{ Pelaksanaan } & $\begin{array}{r}\text { Aktivitas } \\
\text { Pendidik }\end{array}$ \\
\hline & Ya & Tidak & \\
\hline $\begin{array}{l}\text { Membimbing kelompok untuk mendiskusikan } \\
\text { materi }\end{array}$ & & $\sqrt{ }$ & \\
\hline $\begin{array}{l}\text { Memantau jalannya diskusi dan membimbing } \\
\text { kelompok yang mengalami kesulitan }\end{array}$ & & $\sqrt{ }$ & \\
\hline Memberikan kuis individual & $\sqrt{ }$ & & \\
\hline Pendidik bersama siswa menjawab hasil kuis & & $\sqrt{ }$ & \\
\hline Menghitung skor nilai kuis & & $\sqrt{ }$ & \\
\hline Memberikan penghargaan kepada kelompok & & $\sqrt{ }$ & \\
\hline Memandu untuk menyimpulkan materi & $\sqrt{ }$ & & \\
\hline Menyampaikan materi pada pertemuan berikutnya & $\sqrt{ }$ & & \\
\hline Menutup pembelajaran dengan berdoa dan salam & $\sqrt{ }$ & & \\
\hline
\end{tabular}

Tabel 4 menunjukkan aktivitas guru dalam proses pembelajaran menggunakan model kooperatif tipe STAD masih tergolong rendah karena setengah dari semua kegiatan yang direncanakan tidak terlaksana dengan baik. Guru belum terbiasa menciptakan kondisi belajar yang sesuai dengan model kooperatif tipe STAD sehingga guru harus beradaptasi dengan keadaan siswa. Guru tidak menyampaikan mekanisme pembelajaran yang akan dilakukan sehingga sebagian siswa kebingungan dalam menyelesaikan lembar kerja siswa yang dibagikan. Guru belum maksimal dalam memberikan bimbingan terhadap kelompok-kelompok sehingga sebagian siswa tidak termotivasi untuk mengikuti pelajaran yang mengakibatkan siswa tidak memahami materi pelajaran yang dibelajarkan. Data hasil belajar siswa disajikan dalam tabel 5 .

Tabel 5. Distribusi frekuensi tingkat aktivitas siswa pada siklus I

\begin{tabular}{ccc}
\hline \multirow{2}{*}{ Tingkat Aktivitas Siswa } & \multicolumn{2}{c}{ Hasil Pengamatan } \\
\cline { 2 - 3 } & Frekuensi & Persentase (\%) \\
\hline Sangat Aktif & 4 orang & 14,3 \\
Aktif & 5 orang & 17,9 \\
Cukup Aktif & 12 orang & 42,8 \\
Kurang Aktif & 7 orang & 25 \\
\hline
\end{tabular}

Tabel 5 menginformasikan bahwa dari 28 siswa terdapat 4 siswa $(14,3 \%)$ pada tingkat aktivitas sangat aktif, 5 siswa $(17,9 \%)$ pada tingkat aktivitas aktif, 12 siswa $(42,8 \%)$ pada tingkat aktivitas cukup aktif, dan 7 siswa $(25 \%)$ pada tingkat aktivitas kurang aktif. Setelah memberikan tes akhir siklus I, maka diperoleh hasil belajar siswa. Ditinjau dari perolehan nilai hasil belajar sebelum tindakan dan siklus I di tabel 6.

Tabel 6. Data analisis hasil belajar yang dicapai siswa pada siklus I

\begin{tabular}{|c|c|c|c|c|}
\hline \multirow{3}{*}{ Interval Nilai } & \multicolumn{4}{|c|}{ Hasil Penilaian } \\
\hline & \multicolumn{2}{|c|}{ Pra siklus } & \multicolumn{2}{|c|}{ Siklus I } \\
\hline & Frekuensi & Persentase (\%) & Frekuensi & Persentase (\%) \\
\hline $90-100$ & 0 Orang & $0 \%$ & 1 Orang & $3,6 \%$ \\
\hline $80-89$ & 2 Orang & $7,2 \%$ & 6 Orang & $21,4 \%$ \\
\hline $70-79$ & 13 Orang & $46,4 \%$ & 13 Orang & $46,4 \%$ \\
\hline$\leq 69$ & 13 Orang & $46,4 \%$ & 8 Orang & $28,6 \%$ \\
\hline Jumlah & 28 Orang & $100 \%$ & 28 Orang & $100 \%$ \\
\hline
\end{tabular}


Tabel 6 menunjukkan bahwa siswa yang sudah mencapai ketuntasan belajar individual berdasarkan kriteria ketuntasan minimal SMP Negeri 4 Ambon $\geq 70$ (tuntas) pada pra siklus ada 15 siswa $(53,6 \%)$ dari 28 siswa, sedangkan setelah siklus pertama siswa yang mencapai ketuntasan belajar ada 20 siswa $(71,4 \%)$ dan yang belum tuntas 8 siswa $(28,6 \%)$. Berarti setelah siklus I hasil belajar siswa mengalami peningkatan, meskipun ketuntasan siswa secara klasikal masih dibawah target keberhasilan. Hasil belajar pada siklus satu terdapat kenaikan hasil belajar berupa rata-rata kelas dari 63 menjadi 72. Setelah diperoleh hasil belajar, kemudian untuk memberi penghargaan pada kelompok dengan cara skor tes yang didapat dibandingkan dengan skor dasar/skor sebelum tindakan maka didapatlah poin peningkatan individu, kemudian dilanjutkan dengan mencari poin peningkatan kelompok dengan cara merata-ratakan poin peningkatan individu tiap anak dalam satu kelompok. kelompok yang memperoleh peningkatan kelompok tinggi akan diberi penghargaan kelompok. Pada tes siklus 1 ini semua kelompok memperoleh penghargaan yang sama yaitu Team yang baik), dengan point kelompok $\leq 15$.

Berdasarkan hasil yang diperoleh maka dilakukan refleksi untuk memperbaiki dan dilaksanakan pada siklus II. Beberapa kelemahan yang akan digunakan peneliti untuk memperbaiki proses tindakan pada siklus II, yaitu: 1) memberikan motivasi kepada kelompok agar lebih aktif lagi, meningkatkan kerjasama kelompok dalam pembelajaran. 2) lebih intensif dalam membimbing kelompok sehingga siswa akan lebih memahami materi yang diajarkan.

\section{Siklus II}

Hasil observasi terhadap aktivitas guru selama pembelajaran dengan STAD pada siklus II dapat dilihat pada tabel 7.

Tabel 7. Hasil observasi guru pada siklus II

\begin{tabular}{|c|c|c|c|}
\hline \multirow{2}{*}{ Aktivitas Pendidik } & \multicolumn{2}{|c|}{ Pelaksanaan } & \multirow{2}{*}{ Ket } \\
\hline & Ya & Tidak & \\
\hline Membuka pelajaran dengan berdoa & $\sqrt{ }$ & & \\
\hline Memberi motivasi kepada siswa & $\sqrt{ }$ & & \\
\hline Apersepsi & $\sqrt{ }$ & & \\
\hline Menjelaskan tujuan pembelajaran & $\sqrt{ }$ & & \\
\hline $\begin{array}{l}\text { Menjelaskan mekanisme pembelajaran dan penilaian } \\
\text { yang akan digunakan }\end{array}$ & $\sqrt{ }$ & & \\
\hline Menjelaskan materi pembelajaran & $\sqrt{ }$ & & \\
\hline Memberi kesempatan kepada siswa untuk bertanya & $\sqrt{ }$ & & \\
\hline Membagi siswa ke dalam 7 kelompok & $\sqrt{ }$ & & \\
\hline $\begin{array}{l}\text { Membimbing kelompok untuk mendiskusikan } \\
\text { materi }\end{array}$ & $\sqrt{ }$ & & \\
\hline Memantau jalannya diskusi dan membimbing & $\sqrt{ }$ & & \\
\hline kelompok yang mengalami kesulitan & & & \\
\hline Memberikan kuis individual & $\sqrt{ }$ & & \\
\hline Pendidik bersama siswa menjawab hasil kuis & $\sqrt{ }$ & & \\
\hline Menghitung skor nilai kuis & $\sqrt{ }$ & & \\
\hline Memberikan penghargaan kepada kelompok & $\sqrt{ }$ & & \\
\hline Memandu untuk menyimpulkan materi & $\sqrt{ }$ & & \\
\hline Menyampaikan materi pada pertemuan berikutnya & $\sqrt{ }$ & & \\
\hline Menutup pembelajaran dengan berdoa dan salam & $\sqrt{ }$ & & \\
\hline
\end{tabular}


Berdasarkan tabel 7 terlihat bahwa aktifitas guru dalam proses pembelajaran menggunakan model kooperatif tipe STAD sangat baik karena semua langkah-langkah yang direncakan sesuai dengan model pembelajaran kooperatif tipe STAD terlaksana dengan baik. Guru sudah dapat beradaptasi dengan siswa secara baik dan guru membuat ruang kelas lebih kondusif dibandingkan siklus I. Siswa tidak kebingungan lagi dalam mengerjakan LKS yang diberikan karena sebelumya guru telah menyampaikan mekanisme pengerjaannya. Hasil observasi 7 kelompok dapat disimpulkan tingkat aktifitas siswa dalam tabel 8 .

Tabel 8. Distribusi frekuensi tingkat aktivitas siswa pada siklus II

\begin{tabular}{ccc}
\hline \multirow{2}{*}{ Tingkat Aktivitas Siswa } & \multicolumn{2}{c}{ Hasil Pengamatan } \\
\cline { 2 - 3 } & Frekuensi & Persentase (\%) \\
\hline Sangat Aktif & 6 orang & 21,4 \\
Aktif & 15 orang & 53,6 \\
Cukup Aktif & 4 orang & 14,3 \\
Kurang Aktif & 3 orang & 10,7 \\
\hline
\end{tabular}

Dari tabel 8 dapat disimpulkan bahwa pada siklus II dari 28 siswa terdapat 6 siswa $(21,4 \%)$ pada tingkat aktivitas sangat aktif, 15 siswa $(53,6 \%)$ pada tingkat aktivitas aktif, 4 siswa (14,3\%) pada tingkat aktivitas cukup aktif, dan 3 siswa $(10,7 \%)$ pada tingkat aktivitas kurang aktif.

Setelah diberikan tes akhir siklus II, diperoleh nilai hasil belajar siswa. Ditinjau dari perolehan nilai hasil belajar siswa pada siklus II yang telah diperiksa dan diskor dimuat pada table 9 berikut.

Tabel 9. Data analisis hasil belajar siswa siklus II

\begin{tabular}{ccccc}
\hline \multirow{2}{*}{ Interval Nilai } & \multicolumn{4}{c}{ Hasil Penilaian } \\
\cline { 2 - 5 } & Frekuensi & Persentase (\%) & Frekuensi & Persentase (\%) \\
\cline { 2 - 5 } & 1 Orang & 3,6 & 6 Orang & 21,4 \\
$90-100$ & 6 Orang & 21,4 & 11 Orang & 39,3 \\
$80-89$ & 13 Orang & 46,4 & 8 Orang & 28,6 \\
$70-79$ & 8 Orang & 28,6 & 3 Orang & 10,7 \\
$\leq 69$ & 28 Orang & 100 & 28 Orang & 100 \\
\hline Jumlah & & & & \\
\hline
\end{tabular}

Dari tabel 9 menunjukkan bahwa siswa yang sudah mencapai ketuntasan belajar individual berdasarkan kriteri ketuntasan minimal SMP Negeri 4 Ambon $\geq 70$ (tuntas) pada siklus I adalah 20 siswa $(71,4 \%)$ dan yang tidak tuntas 8 siswa $(28,6 \%)$. Sedangkan pada siklus II siswa yang mencapai ketuntasan ada 25 orang $(89,3 \%)$ dan yang belum tuntas 3 orang $(10,7 \%)$. Ini berarti setelah siklus kedua dilaksanakan hasil belajar siswa mengalami peningkatan 17,9\%, yakni rata- rata kelas dari 72 menjadi 81 . Banyak perubahan yang dilakukan guru dan siswa. Salah satu komponen mengelola kelas dengan baik adalah mengembalikan kondisi belajar yang optimal agar tujuan pembelajaran tersebut dapat dicapai dengan baik (Bergin \& Bergin, 2009). Aktivitas siswa yang baik antara lain mengikuti penjelasan guru secara aktif, bekerja sama, menyelesaikan tugas-tugas kelompok, memberikan penjelasan kepada temankelompoknya, mendorong kelompok untuk berpartisipasi secara aktif, berdiskusi dan sebagainya (Le, Janssen, \& Wubbels, 2018). Hal ini berimplikasi pada keberhasilan 
suatu proses pembelajaran yang mengharuskan siswa untuk tidak saja aktif pada saat bekerja secara individu tetapi juga secara berpasangan atau berkelompok.

Hasil analisis hasil tes dan observasi pada siklus II, maka diperoleh hasil refleksi sebagai berikut: 1) mengenai proses pmbelajaran, guru telah melaksanakan kegiatan belajar mengajar sesuai dengan RPP 02 dan siswa telah mengikuti proses pembelajaran dengan baik. 2) hasil penilaian terhadap siswa dalam proses pembelajaran matematika di kelas VII-6 pada siklus II terjadi peningkatan hasil belajar dan ketuntasan siswa secara klasikal sudah melampui target keberhasilan penelitian yang ditargetkan sebesar $85 \%$, yakni $89,3 \%$. Pembelajaran STAD mudah untuk diterapkan, hanya diperlukan pembentukan kelompok-kelompok untuk siswa. Siswa yang sudah dikelompokan bisa berkolaborasi memahami materi (Kordaki, Daradoumis, Fragidakis, \& Grigoriadou, 2012). Jadi model pembelajaran STAD sangat sesuai diterapkan di kelas untuk meningkatkan pemahaman siswa pada konsep matematika.

\section{KESIMPULAN}

Berdasarkan temuan dan pembahasan, maka dapat disimpulkan bahwa penerapan model pembelajaran kooperatif tipe STAD dapat meningkatkan hasil belajar siswa pada materi segi empat, dengan melihat beberapa kriteria sebagai berikut. 1) Hasil belajar matematika siswa sebelum menerapkan model pembelajaran kooperatif tipe STAD, nilai rata-rata 63 dan hanya 53,6\% siswa mencapai nilai $\mathrm{KKM} \geq 70$ (tuntas). 2) Hasil belajar pada siklus I setelah menerapkan model pembelajaran kooperatif tipe STAD terdapat kenaikan hasil belajar berupa nilai rata-rata kelas menjadi 72 dan sebanyak 71,4 \% siswa memperoleh nilai tuntas. 3) Hasil belajar pada siklus II terdapat kenaikan hasil belajar berupa nilai rata-rata kelas menjadi 81 dan sebanyak 89,3 \% siswa memperoleh nilai tuntas. 4). Aktivitas belajar siswa dalam proses pembelajaran matematika dengan menerapkan model ini berada pada kategori baik. Dengan demikian model pembelajaran STAD dapat direkomendasikan untuk meningkatkan pemahaman siswa pada konsep matematika. Implikasi dari pembelajaran ini adalah siswa mengalami perubahan belajar pada konsep matematik pada materi segi empat dan para peneliti dan praktisi pendidikan dapat mengadopsi untuk memperkaya pembelajaran di sekolah.

\section{REFERENSI}

Bergin, C., \& Bergin, D. (2009). Attachment in the Classroom. Educational Psychology Review, 21(2), 141-170. https://doi.org/10.1007/s10648-009-9104-0

Gencosman, T., \& Doğru, M. (2012). Effect of student teams-achievement divisions technique used in science and technology education on self-efficacy, test anxiety and academic achievement. Journal of Baltic Science Education, 11(1), 43-54.

Kordaki, M., Daradoumis, T., Fragidakis, D., \& Grigoriadou, M. (2012). Adapting the collaborative strategy "students team achievement divisions" in an information technology work place. Studies in Computational Intelligence, 408, 131-153. https://doi.org/10.1007/978-3-642-28586-8_6

Le, H., Janssen, J., \& Wubbels, T. (2018). Collaborative learning practices: teacher and student perceived obstacles to effective student collaboration. Cambridge Journal of Education, 48(1), 103-122. https://doi.org/10.1080/0305764X.2016.1259389

McMaster, K. N., \& Fuchs, D. (2002). Effects of Cooperative Learning on the Academic Achievement of Students with Learning Disabilities: An Update of Tateyama-Sniezek's Review. Learning Disabilities Research and Practice, 17(2), 107-117. https://doi.org/10.1111/1540-5826.00037

Ratumanan, G. T. (2016). Motivasi siswa dalam pembelajaran matematika. Di sampaikan dalam seminar nasional pendidikan matematika 2016 pengembangan penelitian pendidikan matematika untuk mendukung peningkatan kualitas pembelajaran matematika [Student motivation in learning mathematics. Delivered in the 2016 national mathematics education seminar development of mathematics education research to support the improvement of the quality of mathematics learning]. Hal 6-13. 
Sofroniou, A., \& Poutos, K. (2016). Investigating the Effectiveness of Group Work in Mathematics. Education Sciences, 6(4), 30. https://doi.org/10.3390/educsci6030030

Sternberg, R. J. (2015). Successful intelligence: A model for testing intelligence beyond IQ tests. European Journal of Education and Psychology, 8(2), 76-84. https://doi.org/10.1016/j.ejeps.2015.09.004

Tarim, K., \& Akdeniz, F. (2008). The effects of cooperative learning on Turkish elementary students' mathematics achievement and attitude towards mathematics using TAI and STAD methods. Educational Studies in Mathematics, 67(1), 77-91. https://doi.org/10.1007/s10649-007-9088-y

Tiantong, M., \& Teemuangsai, S. (2013). Student team achievement divisions (STAD) technique through the moodle to enhance learning achievement. International Education Studies, 6(4), 85-92. https://doi.org/10.5539/ies.v6n4p85

Wang, K. P. (2012). The impact of nursing students' chemistry learning performance assessment in Taiwan: Competitive versus non-competitive student team achievement division approaches. Research in Science and Technological Education, 30(2), 131-149. https://doi.org/10.1080/02635143.2012.687717 